\title{
Preventing the Growing Transmission of COVID Clusters: An Integration of the Maslow's Hierarchy of Needs in the Risk Chain
}

\author{
Huijie Li (D) \\ Jia $X_{u}{ }^{2}$ \\ Tianjiao Xu $\mathbb{D D}^{\prime}$ \\ Long Wang' \\ Liwei Zhang' \\ 'School of Public Administration, Jilin \\ University, Changchun, People's Republic \\ of China; ${ }^{2}$ School of Political Science and \\ Law, Northeast Normal University, \\ Changchun, People's Republic of China
}

Correspondence: Jia Xue School of Political Science and Law, Northeast Normal University, Changchun, People's Republic of China Email xuej060@nenu.edu.cn
Purpose: China's success in containing the coronavirus is an ongoing process of identifying loopholes and refining the management in the COVID-19 risk chain. This article discusses the role of personal needs in epidemic control and linked psychological needs with management measures to propose intervention advice on curbing viral transmission in a systematic way.

Methods: Based on case studies, we showed the integration of the Maslow's Hierarchy of Needs in the COVID-19 risk chain. The analysis combined the micro-view from individual needs and macro influences from governmental measures. The proposed chain of vulnerabilities could help identify critical links of COVID-19 crisis management in case that cascading effects such as super-spread can be intercepted in time.

Results: The article mainly focused on curbing the viral transmission timely whenever cluster of cases resurge. Considering the triggered activities from personal needs may facilitate the spread, minimizing the impact scale while managing the crisis could start with protecting vulnerable population, well governing potential hotspots, and necessary restrictions on group activities. Besides, "individual" protections combined with "institutional" solutions are strongly advocated. The worst scenario would be the governance link slackened or made mistakes, together with delayed identification, plus unprotected way of living and gathering. In order to cut the transmission in time, besides virus-blocking strategies and vaccination approach, screening measures in combination with the satisfaction of personal needs would help identify confirmed cases earlier. Publicizing the model citizen of being responsible could show needs' satisfaction can live with the virus elimination. At the emergency response stage, it is also crucial to secure fewer loopholes in the health system and strengthen the self-protection barrier by all means.

Conclusion: China's experience offers a reference for the balance between the resurgence of clustered cases and sustained recovery. As long as the global pandemic continues, its impact on personal activities will not stop, and vice versa. The chain of vulnerabilities integrating psychological needs into the COVID-19 risk management can provide clear clues for cutting further transmission in an efficient and more socially acceptable way.

Keywords: pandemic control experience, China, COVID-19, risk management

\section{Introduction}

It will take a long time to fight and coexist with the novel coronavirus. ${ }^{1,2}$ The evolving COVID-19 variants could lead to waves of outbreaks, which will sabotage earlier efforts for the combat. Even Israel, which has the highest vaccination rate in the world, cannot be ruled out. As the global pandemic continues, sustained 
lockdown is not possible, while in the incremental recovery process, kinds of activities rising from various subjective needs may expose the citizens to the risk of high infection rates and transmission rates if the COVID-19 virus circulates. Under the circumstances, understanding the role of personal needs in the transmission chain and linking the needs with management measures can clarify those cluster cases in a systematic way and provide clues for cutting the further transmission in an efficient and more socially acceptable way.

The impacts caused by measures taken to contain the spread of the COVID-19 virus on people's daily activities have been deeply studied. ${ }^{3-5}$ Citizens abide by the government's control measures, and their behaviors need to be changed, such as maintaining social distance, wearing masks and mobility restrictions, which lowers people's frequencies of daily communication. ${ }^{6}$ Large-scale anticontagion regulations can stagnate students' classes and people's daily work, which brings inconvenience in life and may further cause social panic. Online classes and telecommuting have become new choices. ${ }^{7}$ However, the uncertainty brought by people's behaviors to the combat of COVID-19 has not been thoroughly studied. Scholars mainly focus on the impact of a single type of group activities or focus on a particular group of people being affected. It is likely to cause mass infection in the community to attend a wedding or funeral as it is a crowded social gathering. ${ }^{8-10}$ International tourism and business travel can lead to the rapid spread of coronavirus across the planet. ${ }^{11}$ Children and the elderly are more vulnerable when confronting the coronavirus, and their activities could induce further spread if they are not well protected. ${ }^{3,12,13}$ Disabled people and their nursing staff are also at greater risk of infections in the time of COVID-19 because of poor management and their own inconvenience. ${ }^{14}$ Patients, hospital staff and restaurant service personnel are more likely to become key communicators and cause more infections in relevant places. ${ }^{15-17}$

Evidently, in times of flattening the resurgent COVID-19 peaks, insufficient food supply, shortage in medical facilities, job loss and other uncertainties have deeply increased people's unsafe feelings and worries about human nutrition, health, education or employment, and friendship, etc, which indicates the government should ensure the basic living security and improve the sense of feeling safe and stable. Since gradually restarting the society while maintaining the public health could last for a long time, it is critical that subjective needs determining the individual behaviors and responses to the COVID-19 should be incorporated into the measures and policies of managing the whole-of-society crisis. ${ }^{18}$ Maslow's Hierarchy of Needs provides a suitable framework for connecting the needs and consequences on society. Scholars from many different disciplines use the Maslow's needs framework to analyze people's behaviors and consequences related to the pandemic. By observing individuals who experienced loneliness, pressure, and other mental health problems caused by lockdown, the link between negative emotions and the first three levels of Maslow's needs has been demonstrated. ${ }^{19}$ Some researchers insist there is no evidence showing the pandemic has a negative impact on the restaurant, as people have their basic needs. ${ }^{20}$ Weddings, however, could cause mass contagion. Hugging, hand shaking and other close-contact behaviors during the larger gathering will trigger a potential transmission among secondary contacts. ${ }^{8}$ Following wedding party events, religious gatherings were estimated to have the second highest infection spread among types of cluster activities, while industrial agglomeration is estimated as the lowest. ${ }^{21}$ The surge of cases caused by hospital infections is notable, especially at the beginning of the pandemic. People still need to go to hospital, but with concern about being infected. Poor ventilation, crowded visitors and patients vulnerable to diseases could induce further spread and exacerbate the shortage of medical resources once hospitals become the transmission hotspot. ${ }^{22}$ To minimize the infection risk in hospitals, it is recommended wearing universal masks, restricting visitors, separation measures and donning and doffing monitors according to the standard. ${ }^{23}$ As the epidemic situation has improved, with more sufficient physical survival requirements in place, the needs level of people could rise. Autonomy, competence, and relatedness then need to be fulfilled rather than a "luxury good" during the outbreak. ${ }^{24}$ Non-essential service fulfills the higher-order needs, such as esteem and self-actualization. A study found that the customers' desires would transfer from stockpiling goods to the high-quality buying experiences (eg, face-toface interactions) in times of lockdown. ${ }^{25}$ Travel needs contributed to the recent resurgence of many outbreaks in different parts of China, particularly when there are management loopholes in the airport and at the scenic spots. ${ }^{26-29}$ For the social connectedness, although long-term social distancing has boosted the advancement of digital technology in online work and life, there are still groups of people like elderly offline and professionals becoming much busier than ever should not be forgotten. Healthcare workers and hospital personnel need physical and psychological security, as well as social attachment and the meaning of life and work. ${ }^{30}$ 
In sum, the current research mainly focused on the impact of viral transmission and pandemic control on people's lives. The impact of personal needs on coronavirus transmission has not been paid enough attention. Although a few studies analyze cases with Maslow's Hierarchy of Needs, they normally focused on specific needs and do not consider all need types in the research. Besides, these studies also failed to establish a chain between individual needs, epidemic control and cluster infection, and thereby could not effectively help prevent the risks caused by different types of needs. Timely control measures can prevent the handful of COVID-19 cases from becoming clusters ${ }^{31,32}$ and prevent those clusters becoming community transmission, which will largely reduce the risk of medical system breakdown. This article illustrates five cases during China's fight against the pandemic to show the integration of the Maslow's Hierarchy of Needs in the risk chain. The analysis will combine the micro-view from individual needs and macro influences from governmental measures. The proposed chain of vulnerabilities could help identify critical links of COVID-19 crisis management in case that cascading effects such as super-spread can be intercepted in time. On one hand, China's experiences may be of help to other low- and middle-income countries in their fight against COVID19. On the other hand, this study has three major contributions to the analysis of preventing the potential transmission, meanwhile not neglecting personal needs. Firstly, the study tries to connect micro personal needs with macro control needs, which can provide a win-win strategy for dealing with the COVID-19 crisis. Secondly, identifying tipping points can help guard against cluster outbreaks at lower control costs. Thirdly, the present studies focused more on negative impacts of individual's needs and behaviors on the pandemic control, while this article adds the positive evidence that inspiring the sense of responsibility and the satisfaction of higher-level needs such as self-fulfillment could help cut the transmission chain as early as possible, which is now being underestimated.

\section{Case Study: Vulnerability Analysis Integrating the Maslow's Hierarchy of Needs}

According to Maslow, ${ }^{33}$ human behaviors are motivated by five basic categories of needs that include physiological needs, safety needs, social needs, esteem needs, and self- actualization needs, often displayed as hierarchical levels within a pyramid. Physiological needs refer to the basic needs of living, such as the need for food, sleep and warmth, and physical health during the pandemic in particular. Safety needs relate to the attempts to feel safety, seek security and stability, while they include the risk of COVID-19 infections, and the loss of order and control of lives when confronting the pandemic. Social needs refer to needs for love and belongingness, while social distancing could erode the relationship with others. Esteem needs include needs for self-worth, respect and recognition, whereas self-actualization needs contain needs for personal growth and self-fulfillment.

In order to present the context of human needs and activities that induce further transmission, we collect data and case details of COVID cluster infections from Chinese official reports and authorized media news for this explorative study. We use the case study approach ${ }^{34}$ to offer deeper insights into the local outbreaks with detailed information about individual experiences of confirmed cases and governmental interventions, which may not be achieved by other research methods. Nevertheless, firsthand empirical studies with more detailed investigation are needed for our subsequent research to develop more thorough knowledge about the transmission risk chain.

The Appendix Table illustrates community outbreaks in China after the Wuhan outbreak peak, which shows the continuous challenges from the border and the cold chain imports. For human needs, which may facilitate the viral transmission, it shows no clear disparities among regions, and during the recovery period the threats posed by the work safety (confirmed cases in Dalian) and the tourism safety (recent confirmed cases in Nanjing, Zhangjiajie, Ejina Banner), intertwining with increasing travels, business or family visits and more social interactions, bring potential exposure risks to schools and universities via family transmissions if the cases cannot be identified earlier. The Appendix Table shows that social/belonging needs and safety needs are top important triggers for the further spread of COVID19 in local China. However, there are few cases related to esteem needs and self-actualization needs, because news reports mention more the negative impacts of human activities. To be clear, the five cases we discuss here are selected considering the information completeness about the transmission risk chain and whether they mainly refer to the corresponding level of needs. After 


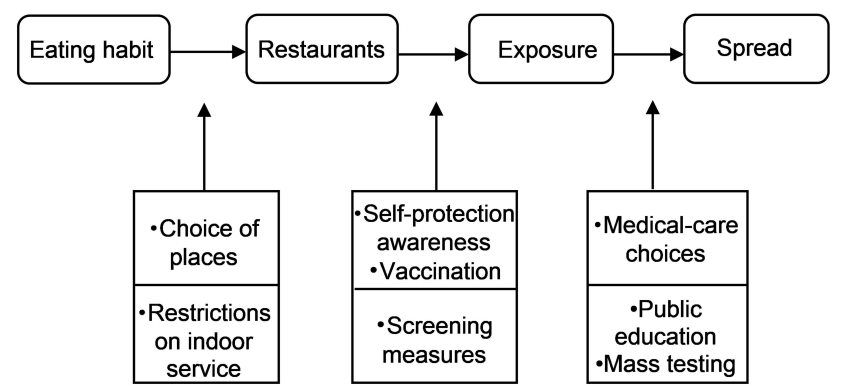

Figure I The chain of vulnerabilities that cause cascading effects of virus transmission by physiological needs.

filtering this criterion, we could not find more detailed cases as discussed below.

\section{Case I: Physiological Needs}

Food is essential to human survival, and dietary habits are not easy to be changed. During the recovery period, virus variants can still pose a threat to the resurgence when the catering business reopens. According to the analysis of the confirmed cases in Guangzhou (see Figure 1), the transmission of COVID-19 may be caused by failing to pay attention to restrictions on indoor service and self-protection in restaurants while dining to satisfy basic needs.

The first case identified in Liwan District of Guangzhou City kept the eating habit of going to a restaurant early in the morning for dim sum on 19 May 2021, and he walked to the hospital for medical treatment due to discomfort on the second day. Because of exposed to public occasions, he not only infected COVID19 to his family members but also infected the restaurant attendants and diners, thus the contagion expanded. ${ }^{35}$ Since the first case was confirmed in Liwan District on May 21, as of June 3, the epidemic infection number in this chain has increased to $77 .{ }^{36}$

Figure 1 tries to identify the chain of vulnerabilities that cause cascading effects of virus transmission by physiological needs in the cases of Guangzhou. For restrictions on indoor service during the regular control period, catering service units should implement the health regulations and continue the health monitoring of employees. Besides, the health code check, temperature measurement and wearing masks (at least by the waiters) had not been implemented strictly in restaurants. The waitress, who once served the first identified a morning meal, was diagnosed as asymptomatic with no mask during the food delivery. During the recovery period, people tend to forget wearing masks in public places, for that, public education on self-protection should be strengthened. Another problem is, before this wave of transmission, the vaccine coverage is not enough. Elderly people are still vulnerable. Although self-medication delays the first identified person's treatment a little bit, walking to see the doctor decreases the possibility of infecting other people on the way.

Besides, the Liwan District transmission was ceased in time due to timely control measures. On the one hand, to track the activity and contact persons of the confirmed cases and asymptomatic carriers, the government carried out an in-depth epidemiological investigation, and found out all the close contacts and sub-close contacts who then had been in centralized isolation for further observation. On the other hand, the local government strengthened COVID-19 nucleic acid detection and screening the mass. After 4 days of continuous investigation, as of 14:00 on 24 May, 131,226 samples were collected, and 129,758 nucleic acid tests were completed. ${ }^{37}$ To learn from this lesson in combatting COVID-19, the local government put forward various requirements for the catering industry. Influenced areas can resume indoor business only after they are assessed as qualified in strict accordance with the specifications. Catering service units should have regular disinfections, control the number of diners in catering places, and enlarge the table spacing. ${ }^{38}$

\section{Case 2: Safety Needs}

People need to obtain timely and reliable medical treatment when necessary. If the epidemic prevention regulations are not strictly implemented in hospitals, plus the large flow of people and closed space within, the hospitals themselves could become hotspots accelerating the virus spread. For the cases of Harbin City (Heilongjiang Province), it was found that there are loopholes in hospital epidemic management, and patients and caregivers did not follow self-protection rules. And then their families and friends contributed to the further spread of COVID-19.

From April 2 to 6 of 2020, the first case identified in Harbin was hospitalized in Harbin's Second Hospital for the stroke reason. But he did not get the nucleic acid test as required because of showing no symptoms of fever. He was afterwards transferred to the respiratory department of the First Hospital of Harbin Medical University by the ambulance. The first responsible doctor did not ever think he could be a confirmed case because the ambulance transporters did not wear protective clothing. The doctor on duty at the respiratory department of the First Hospital 
where the first case was confirmed later also believed that the patient was not at the risk of coronavirus infection. So, he was still not required to get the nucleic acid tests and directly arranged into an ordinary 8-person ward. In addition, the first case identified has 3 caregivers, violated the "one patient, one caregiver" rule. With caregivers at the respiratory department frequently chatting with each other and moving around, the transmission continued. ${ }^{39}$ As of April 25, 2020, there were more than 80 confirmed cases and asymptomatic infections. ${ }^{40}$ Besides, two doctors and six nurses from Harbin Second Hospital were also infected, and there were another 405 medical staff once isolated for observation. Failing to carry out pre-hospital nucleic acid tests and the lack of attention paid to COVID19 are the two primary causes for the Harbin outbreak. The first case identified in Harbin was placed in an 8-person ward, lacking of isolation measures due to the screening failure. In addition, caregivers lacked the awareness of self-protection, and their frequent chatting in the corridor close to the nurse station triggered the further spread of the virus. Moreover, as caregivers accompany patients for various medical examinations, the virus then circulated in the shared facilities open to the public. ${ }^{39,40}$

On April 17 of 2020, the Heilongjiang Provincial Commission for Discipline Inspection and Supervision held 18 local party members and public officials accountable. ${ }^{40}$ After that, the government officials and the public paid more attention to the COVID-19 fight. In order to prevent further spread of the epidemic, the two hospitals had carried out nucleic acid tests on all medical staff, patients in hospital, and patients in and out of hospital within 14 days. And outpatient registration was changed from on-site to online. ${ }^{40}$ For the whole country fight, the National Health Commission of China issued technical guidelines of preventing and controlling the COVID-19 infections for medical institutions and emphasized the importance of hospital infection control regularly alongside the updated epidemic status. Hospitals, in case of becoming hotspots for transmission, should have strengthened internal management and supervise medical staff to avoid unnecessary risks in accordance with process standards. Particularly for those hospitals that treat imported confirmed cases, the infection control performance deserves greater attention. Recently, about one hundred confirmed cases could trace from the failure of infection control of a hospital in Zhengzhou City of China. ${ }^{41}$ We need to constantly keep vigilant against COVID fatigue and slackness, especially for hospitals (Figure 2).

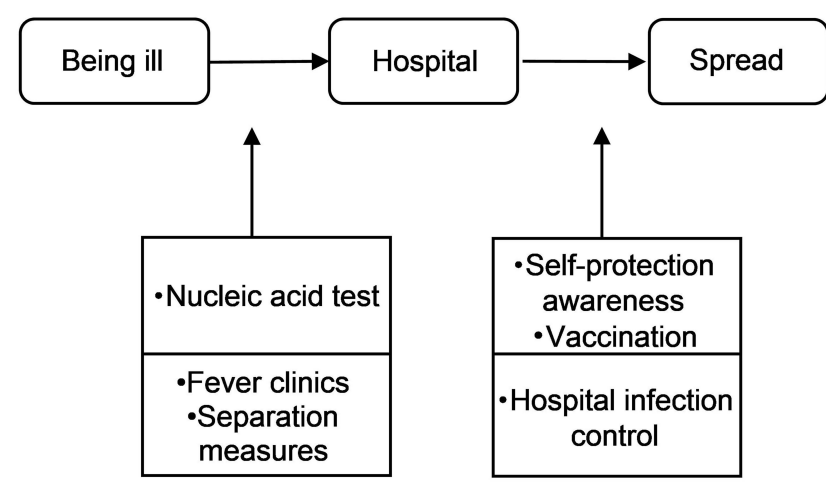

Figure 2 The chain of vulnerabilities that cause cascading effects of virus transmission by belonging needs.

\section{Case 3: Belonging Needs}

Humans need to have relationships with others. Belonging needs are the feelings associated with a group, such as love, affection and so on, coming from family, friends, and other relationships. People are all eager to establish mutual connections with others, and to integrate into a certain group, as well as during the pandemic. ${ }^{42}$ Physical distancing and restrictions on gathering activities may lead to loneliness, anxiety, depression and other psychological outcomes. ${ }^{43}$ During the regular control periods when the fear of being infected is no longer the predominant emotion, the need for social interaction could trigger activities facilitating the spread of COVID-19 based on the analysis of the Hebei cases.

In Hebei Province, a 61-year-old person was confirmed as the case of COVID-19 on January 2, 2021. Before that, there were hardly any infections in rural communities. The attention to fight against COVID-19 was paid more to cities. But after the New Year holiday, China reported clusters of infections in multiple provinces (eg, Hebei, Heilongjiang, and Jilin), the majority of which broke out in rural areas and many patients are elderly people. On January 13 of 2021, China reported its biggest jump of daily COVID-19 cases since March 5, 2020. ${ }^{44}$ The outbreak in Hebei shows the weakness of rural areas in combating COVID-19: poor health facilities and quarantine limitations could ravage whole rural communities.

Figure 3 tries to identify the chain of vulnerabilities that led to the super spread in the rural areas from the very beginning. The rural elderly group has their needs and behavior patterns rooted from social customs, which have potential impacts on the COVID-19 control. Mahjong playing, neighbor visiting, square dancing and other 


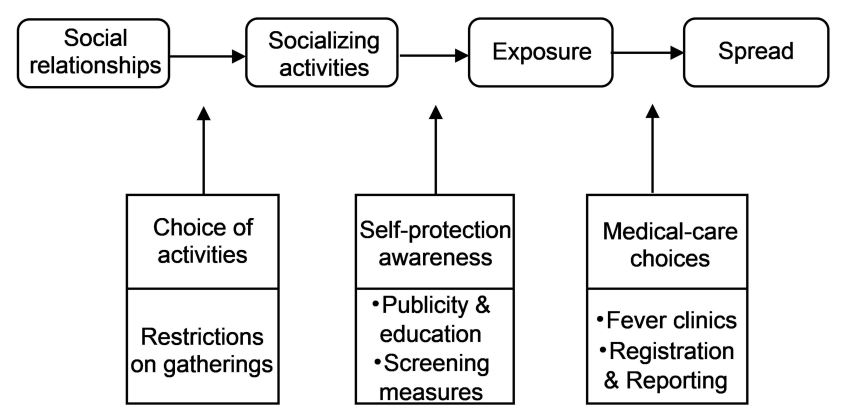

Figure 3 The chain of vulnerabilities that cause cascading effects of virus transmission by safety needs.

gathering activities are important for the rural elderly to socialize. Frequent inside interactions, gathering activities such as regular fairs and occasional events (eg, funerals and weddings) are typical ways to spend daily time, which can be found in many confirmed cases of Hebei and Heilongjiang provinces. Multiple times of wedding attendances without wearing masks during the New Year holiday accelerated the virus spread. Moreover, the elderly people in China tend not to see the doctor when they are ill, and the utilization rate of hospitalization services of rural residents is much lower. ${ }^{45,46}$ Many patients had visited village clinics before they were confirmed. Rural residents prefer to choose the common practice in villages-intravenous therapy, which creates obstacles for early detections and may lead to cross-infections. From the management perspective, almost back to "normal" life combined with few earlier cases, gradually loosened the nerves of local government and rural residents. Lack of restrictions on indoor gatherings, loosened monitor of people returning home from risky regions and other management loopholes (eg, slackened management for the village screening and lack of public education for the COVID-19 infections) also contribute to the super spread. The worst scenario would be that rural elderly keep their intensive interactive gatherings without wearing masks and do not go to see a doctor when fever and cough symptoms are shown, meanwhile there are management loopholes of the epidemic control, which is just the Hebei case.

Immediately after the outbreak, combination strategies were implemented such as restrictions on gatherings, screening measures at village entrances for checking temperature and health code, publicizing the importance of wearing masks, and mass testing to separate the virus carriers to stop the community transmission as early as possible. Village doctors and medicine shops are demanded to guide filtered villagers to fever clinics in a timely and standardized manner. To increase the screening efficiency of suspected patients, some local governments suggest township hospitals and village clinics should be integrated as epidemic monitoring and reporting sites. These measures tend to be effective and this wave of local transmission ceased on February 7 of 2021.

\section{Case 4: Esteem Needs}

When someone makes a contribution to the society, he or she feels self-worth or gains recognition and respect from others, and then his or her esteem needs are fulfilled. The pandemic has cut some group fun to satisfy esteem needs or some interactive opportunities for individuals to win others' recognition, but many citizens stand out by contributing as a volunteer or set up self-groups, which help people in need with supply delivery, medical assistance and in other means.

In Beijing, the man, before confirmed on June 11 of 2020 , went to the fever clinic by bike immediately after he showed up fever symptoms. Out of respect for self and others, he has a good habit of wearing a mask whenever necessary and also told others to do so. Therefore, none of his relatives and friends were confirmed. Due to his prompt report and clear recall of all the places he had been and a detailed name list he had contacted after he was confirmed, the exposed places and population could be separated earlier, and the source of this wave of outbreak-the Xinfadi market was soon located. His good memories out of sense of responsibility were crosschecked by the big data of his travel. It turns out that they do match. ${ }^{47}$

Surrounding the Xinfadi market, mass testing for COVID-19 and other control measures were performed to stop the transmission rapidly. The information and responsible behaviors of this first identified case provided the important basis for that. He also set an example for others to report self-travel histories and go to fever clinic with good self-protection without delay. Even experts said that the actions of the first confirmed person greatly increased their confidence in winning the COVID-19 fight. Indeed, containing the virus transmission cannot succeed without these self-disciplined and responsible actions of individuals. The epidemiological investigation and big data cannot function without the permission of citizens. ${ }^{48}$ Some people monitor their health conditions themselves at home consciously, some people choose not 


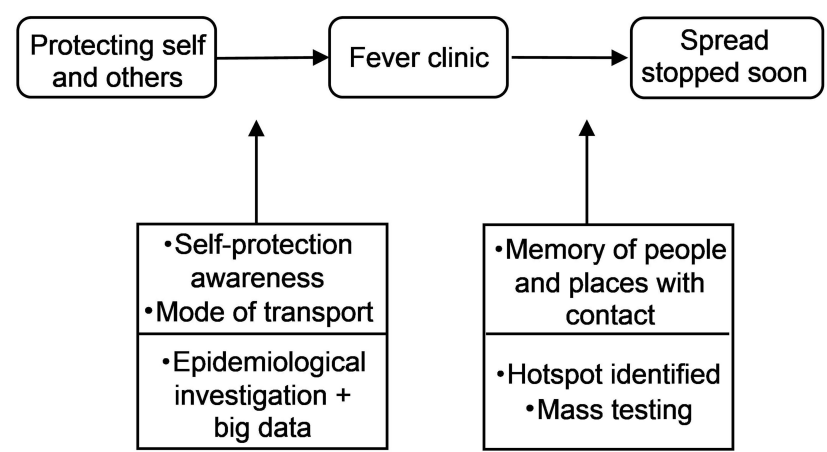

Figure 4 The chain of vulnerabilities that cause cascading effects of virus transmission by esteem needs.

to travel unless necessary, some people follow local regulations strictly after traveling back from risky areas. Everyone matters in the fight against the pandemic (Figure 4).

\section{Case 5: Self-Actualization Needs}

Affected by the pandemic, some people lose their jobs or could not earn more money or get promotion as usual. For self-development, many citizens choose to continue their studies. However, many examinations and learning activities have been cancelled or postponed, which further suppressed people's needs for self-improvement.

On December 22 of 2020, a resident of Shunyi District in Beijing had the nucleic acid test as required for taking part in the postgraduate entrance examination. On the next day, he was confirmed positive for the coronavirus. Relevant departments contacted him immediately, hoping that he would recall his whereabouts and close contacts in the past 14 days and help locate the source of the virus as soon as possible. ${ }^{49}$ Emergency management was initiated immediately by Shunyi District. For example, the epidemiological investigation was carried out timely. As of December 23, 2020, a total of 260 close contacts (subclose contacts included) including fellow passengers, passengers on the same flight, taxi drivers, hotel and restaurant service staff have been investigated, and 10 of them were from other cities. Various prevention and control measures such as centralized isolation control, nucleic acid testing, and trace tracking and co-investigation have been implemented. ${ }^{50}$

The first case identified of Shunyi District in Beijing has the need of self-development to continue his studies. He followed the corresponding regulations for the entrance examination and had the nucleic acid test as required. It shows that some screening measures could help identify the infections, especially for large group events to satisfy certain needs, otherwise cluster of cases might possibly surge. Due to the adoption of appropriate control measures in time, the transmission chain was clarified soon. Therefore, this case did not bring about too much panic or negative effects in a large scale.

\section{Conclusion: Needs Satisfaction and COVID-I 9 Control}

China has gone through a "normal" period after successfully containing the coronavirus. Actually, it is an ongoing process of identifying loopholes and refining the management in the COVID-19 risk chain. The path to sustained recovery from the pandemic cannot work without socially acceptable strategies to minimize social and economic repercussions of restrictive measures. ${ }^{18}$ The control of coronavirus spread and its impact is highly dependent on individual reactions, no matter whether actively or passively. Besides, in different stages of fighting against the COVID-19, people tend to have different needs in dominance. People could also loosen nerves and make mistakes in the epidemic control procedures. China's local outbreaks in Nanjing Airport, and further spread through the scenic spot in Zhangjiajie, show the individual needs for travel, for pleasure or family visiting, could put them at risk, particularly when COVID-19 variants are not effectively blocked outside and the governmental or organizational combatting measures could not follow up the human needs for necessary adjustments. Therefore, this article suggests governmental measures should consider personal needs during the regular control period based on the risk chain analysis. It originated from human actions and reactions, which reflect their psychological needs, which provide clues for the intervention points in the COVID-19 crisis management.

China's experiences may be of help to countries in the tough fight against COVID-19 as confirmed cases resurge. From the analysis, it was found that the worst scenario would be the governance chain slackened or made mistakes, together with delayed identification, plus unprotected way of living and gathering. The new wave of local outbreaks in China (see Appendix Tables) shows that the vaccination could not provide $100 \%$ protection for individuals and people still need to wear masks in closed space or at gathering events. From the case 5, screening measures in combination with the satisfaction of personal needs indeed help identify confirmed cases earlier. On the other side, if the screening measures fail 
as shown in the cases $1-3$, the chain of vulnerabilities that may cause cascading effects such as super-spread could bring about severe adverse effects both on the health and economy over time and space, the interception of which would be more difficult. In those cases, testing in a larger scale as mass screening has to be used, as China sticks to the "zero tolerance" approach. More importantly, to reduce the pandemic impacts on citizens' lives, China's routine prevention strategy is to block the coronavirus outside local communities, with strict control on returnees from abroad, and regular checks of key population who work in the cold chain industry, customs, hospitals, airports, etc. Nevertheless, the virus mutations together with loosened nerves and control fatigue pose additional challenges and then outbreaks may re-emerge. The management loopholes in Nanjing Airport induced further transmission of coronavirus in many provinces of China. Increased human mobility and social activities accelerated the spread. Under the circumstances, to ensure personal needs are met while managing the crisis, the model citizen as shown in case 4 would be important, to navigate people to live as responsible citizens. Everyone is important in the fight against COVID-19. Living with the virus or eliminating the virus does not conflict with individuals' satisfaction of esteem, self-fulfillment, and other needs.

The COVID-19 pandemic has changed many facets of our lives, whether we are rich or poor, male or female, young or old, educated or illiterate. We all have to face those challenges it brings. Although we have different needs and expectations at different times, according to Maslow's Hierarchy of Needs, we share the same structure of needs and perform similar activities to satisfy the needs. Through the integration of Maslow's Needs framework and the vulnerabilities illustrated in the risk chain, we try to find the interconnection between individual needs, governmental interventions and behavior guidance, so as to propose suggestions for control measures to minimize their impacts on citizens' lives. It advocates "individual" protections (Figures 1-4, the upper half) together with "institutional" solutions (Figures 1-4, the lower half) for the pandemic control. The proposed chain of vulnerabilities could help identify critical links of COVID-19 crisis management and cut the transmission chain as soon as possible. The article mainly focused on curbing the transmission faster whenever cluster of cases resurge. Therefore, considering the triggered activities from needs may facilitate the spread, during the emergence response period of combatting COVID-19, minimizing the impact
Table I Recommendations for Intervention Points After the Resurgence of Cluster Cases

\begin{tabular}{|l|c|c|c|}
\hline $\begin{array}{l}\text { Intervention } \\
\text { Point }\end{array}$ & $\begin{array}{c}\text { Key } \\
\text { Population }\end{array}$ & Hotspots & $\begin{array}{c}\text { Group } \\
\text { Activities }\end{array}$ \\
\hline Example & Elderly people & $\begin{array}{c}\text { Hospitals, } \\
\text { clinics }\end{array}$ & $\begin{array}{c}\text { Big events such as } \\
\text { weddings and } \\
\text { funerals }\end{array}$ \\
\hline Case & $\begin{array}{c}\text { Hebei } \\
\text { Province, } \\
\text { Guangzhou } \\
\text { City }\end{array}$ & $\begin{array}{c}\text { Harbin City, } \\
\text { Hebei } \\
\text { Province }\end{array}$ & $\begin{array}{c}\text { Hebei Province, } \\
\text { Heilongiang } \\
\text { Province }\end{array}$ \\
\hline
\end{tabular}

scale could start with protecting vulnerable population, well-governing potential hotspots, and necessary restrictions on group activities, as shown in Table 1. Learning from past experiences, at the emergency response stage, it is crucial to identify infection hotspots as early as possible, with strict infection control in hospitals and normal clinics as "scout" for possible COVID-19 infections, securing less loopholes in the health system and hindering the speed of transmission.

Last but not least, each of us have to face the lives being changed by COVID-19, but the impacts differ. The case studies indicate the elderly group is playing a critical role in combatting the COVID-19. Not only because they are at a higher risk of mortality and severe disease after being infected, ${ }^{3}$ they need social interaction to relieve loneliness and tend to stick to old habits in comparison with other age groups. They could be left behind and forgotten in the Era of digitalization (see Figure 5).

When elderly people perform activities to satisfy their needs, intended and unintended consequences (eg, morning tea in restaurants for Guangzhou transmission, wedding events for Hebei transmission, marketing events for Jilin transmission, mahjong playing for recent Yangzhou transmission) may create obstacles for epidemic control and lead to further spread over time and space. Therefore, the very activity brings elderly as an integral factor in the whole epidemic control picture. On January 20 of 2021, 144 COVID-19 infections have been found to be linked to a traveling salesman to Jilin Province, which can further trace the transmission from the Heilongjiang cases. All the people who attend the salesman's health-related marketing event are all over 60 years old, with more than a half have been confirmed. Among the Jilin reported infections till Jan. 20, 62.53\% are above 60 years old, and the oldest is 92. ${ }^{53}$ Similarly, the early infected people in Yangzhou in 


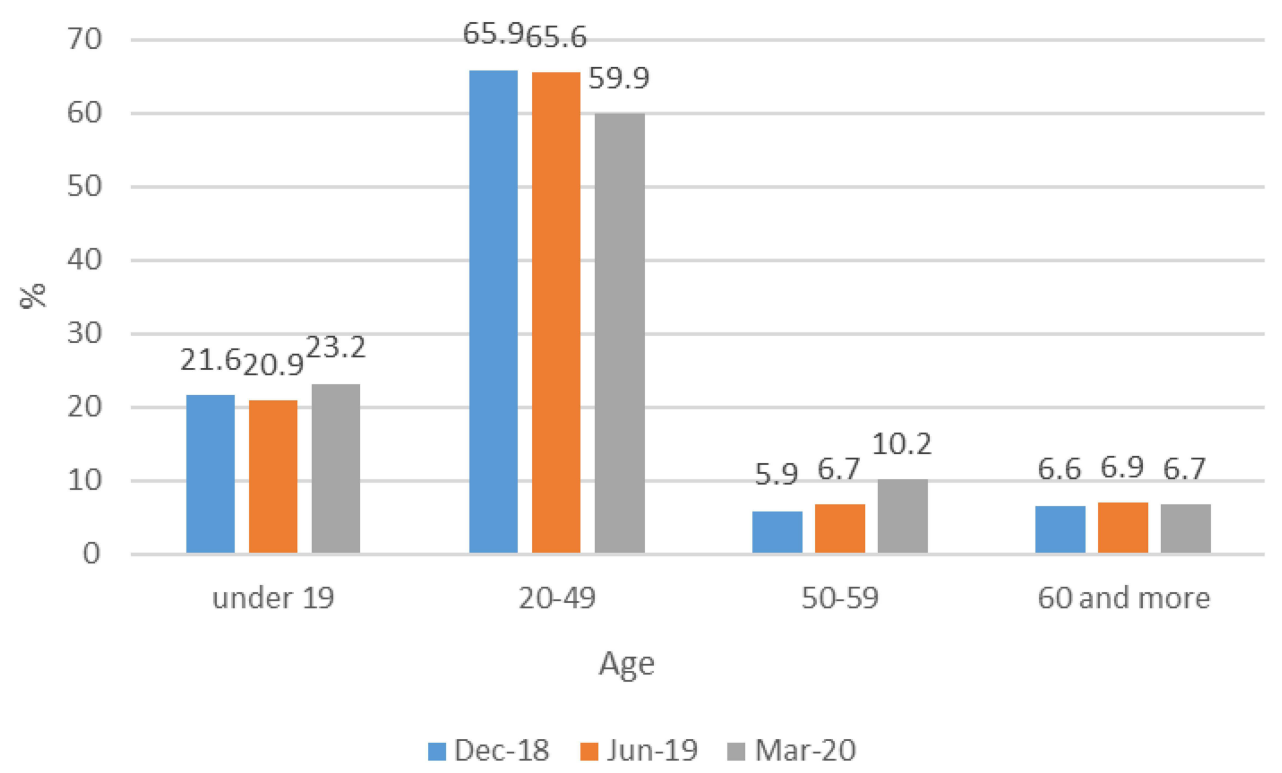

Figure 5 The age structure of Internet users in China.

Note: Data Source: The 44th and 45th China Statistical Report on Internet Development. ${ }^{51,52}$

August 2021 were mostly the elderly. They flow between different chess and card rooms with no protective measures, resulting in the emergence of multiple outbreaks in a short time. ${ }^{54}$ These choices or actions made by the elderly are associated with special concerns behind. Once vulnerabilities identified in the risk chain, crisis management would be much clearer that how to prevent, reduce those consequences by choosing appropriate measures. For example, during the outbreak period, they can be suggested staying home if possible as gatherings enhance the risk of being infected. Wear masks when physical distancing is difficult, which protects attendees at gatherings. Individuals with fever and cough symptoms should be guided to proper hospital care, or delayed treatment may put families and communities at higher risks of infections and rapid spread. From the management perspective, the government tried to protect citizens by blocking the coronavirus outside local communities with various screening measures. In addition, people above age 60 are suggested to take vaccine shots since this March after clinical test results are encouraging and the health condition of individual elderly is sufficiently evaluated. ${ }^{55}$ At the emergency response stage, regulating group activities is necessary. During the Chinese Spring Festival holidays (soon after the Hebei outbreak), the government advised off-peak travel or local Spring Festival, considering that mass migration of (young) workers may lead to higher risks, particularly for rural elderly. It proved that the advice on stay put was effective. There is no rebound during the Spring Festival holidays until domestic cases resurge in Ruili City in Yunnan Province on March 29 of 2021 due to the difficulty of border control. According to the media report, about 0.1 billion population stay where they work which indicates the reduction of at least 0.2 billion times of travel. ${ }^{56}$

\section{Informed Consent Statement}

Patient consent was waived for this study, due to the data of individual case descriptions were all obtained from published Chinese official report and media news. Besides, this study is non-interventional, where ethical approval can be waived.

\section{Acknowledgments}

The authors are grateful to the anonymous referees for their insightful comments to improve the quality of this article.

\section{Funding}

This work was supported by the National Social Science Fund for Young Scholars (grant number 18CZZ010); the Social Science Fund for Young Scholars of Jilin Province (grant number 2021C18); the Research Project fund for Young Scholars of Northeast Normal University (grant number 21XQ022); and the Fundamental Research Funds of Jilin University for Philosophy and Social Science Research Project (grant number 2021ZZ011).

\section{Disclosure}

The authors report no conflicts of interest in this work. 


\section{References}

1. López L, Rodó X. The end of social confinement and COVID-19 re-emergence risk. Nat Hum Behav. 2020;4:746-755. doi:10.1038/ s41562-020-0908-8

2. Anderson RM, Hollingsworth TD, Baggaley RF, Maddren R, Vegvari C. COVID-19 spread in the UK: the end of the beginning? Lancet. 2020;396(10251):587-590. doi:10.1016/S0140-6736(20)316 89-5

3. United Nations. Policy brief: the impact of COVID-19 on older persons; 2020. Available from: https://www.paho.org/en/documents/ policy-brief-impact-covid-19-older-persons. Accessed February 1, 2021.

4. Zhang C, Zhang J, Qiu X, et al. Deep brain stimulation for Parkinson's disease during the COVID-19 pandemic: patient perspective. Front Hum Neurosci. 2021;15:628105. doi:10.3389/fnhum.20 21.628105

5. Fairlie R, Fossen FM. The early impacts of the COVID-19 pandemic on business sales. Small Business Econ. 2021;5:1-12. doi:10.1007/ s11187-021-00479-4

6. Al-Hasan A, Yim D, Khuntia J. Citizens' adherence to COVID-19 mitigation recommendations by the government: a 3-country comparative evaluation using web-based cross-sectional survey data. J Med Internet Res. 2020;22(8):e20634. doi:10.2196/20634

7. Sun HC, Liu XF, Xu XK, Wu Y. Analysis of COVID-19 spreading and prevention strategy in schools based on continuous infection model. Acta Phys Sin. 2020;69(24):240201. doi:10.7498/aps.69.20 201106

8. Yusef D, Hayajneh W, Awad S, et al. Large outbreak of coronavirus disease among wedding attendees, Jordan. Emerg Infect Dis. 2020;26 (9):2165-2167. doi:10.3201/eid2609.201469

9. Ripabelli G, Sammarco ML, Cannizzaro F, Montanaro C, Ponzio GV, Tamburro M. A coronavirus outbreak linked to a funeral among a Romani community in central Italy. Front Med (Lausanne). 2021;8:617264. doi:10.3389/fmed.2021.617264

10. Kant R, Zaman K, Shankar P, Yadav R; RMRC GKP COVID Diagnostic Team. A preliminary study on contact tracing \& transmission chain in a cluster of 17 cases of severe acute respiratory syndrome coronavirus 2 infection in Basti, Uttar Pradesh, India. Indian J Med Res. 2020;152(1-2):95-99. doi:10.4103/ijmr.IJMR 291420

11. Lew AA, Cheer JM, Haywood M, Brouder P, Salazar NB. Visions of travel and tourism after the global COVID-19 transformation of 2020. Tour Geograph. 2020;22(3):455-466. doi:10.1080/14616688. 2020.1770326

12. Ji LN, Chao S, Wang YJ, et al. Clinical features of pediatric patients with COVID-19: a report of two family cluster cases. World $J$ Pediatr. 2020;16:267-270. doi:10.1007/s12519-020-00356-2

13. Xu XK, Liu XF, Wu Y, et al. Reconstruction of transmission pairs for novel coronavirus disease 2019 (COVID-19) in mainland China: estimation of superspreading events, serial interval, and hazard of infection. Clin Infect Dis. 2020;71(12):3163-3167. doi:10.1093/cid/ ciaa790

14. Rotarou ES, Sakellariou D, Kakoullis EJ, Warren N. Disabled people in the time of COVID-19: identifying needs, promoting inclusivity. J Glob Health. 2021;11:03007. doi:10.7189/jogh.11.03007

15. Tan LF. Preventing the transmission of COVID-19 amongst healthcare workers. $J$ Hosp Infect. 2020;105(2):364-365. doi:10.1016/j. jhin.2020.04.008

16. Yu X, Yang R. COVID-19 transmission through asymptomatic carriers is a challenge to containment. Influenza Other Respi Viruses. 2020;14(4):474-475. doi:10.1111/irv.12743

17. Liu T, Gong D, Xiao J, et al. Cluster infections play important roles in the rapid evolution of COVID-19 transmission: a systematic review. Int $J$ Infect Dis. 2020;99:374-380. doi:10.1016/j.ijid.20 20.07.073
18. Ryan BJ, Coppola D, Canyon DV, Brickhouse M, Swienton R. COVID-19 community stabilization and sustainability framework: an integration of the Maslow hierarchy of needs and social determinants of health. Disaster Med Public Health Prep. 2020;14 (5):623-629. doi:10.1017/dmp.2020.109

19. Cerbara L, Ciancimino G, Crescimbene M, et al. A nation-wide survey on emotional and psychological impacts of COVID-19 social distancing. Eur Rev Med Pharmaco. 2020;24(12):7155-7163. doi:10. 26355/eurrev 20200621711

20. Gunay S, Kurtulmuş BE. COVID-19 social distancing and the US service sector: what do we learn? Res Int Bus Financ. 2021;56:101361. doi:10.1016/j.ribaf.2020.101361

21. Saidan MN, Shbool MA, Arabeyyat OS, et al. Estimation of the probable outbreak size of novel coronavirus (COVID-19) in social gathering events and industrial activities. Int $J$ Infect Dis. 2020;98:321-327. doi:10.1016/j.ijid.2020.06.105

22. Yang Y, Wang H, Chen K, Zhou J, Deng S, Wang Y. Shelter hospital mode: how do we prevent COVID-19 hospital-acquired infection? Infect Control Hosp Epidemiol. 2020;41(7):872-873. doi:10.1017/ice.2020.97

23. Oliver D. Could we do better on hospital acquired COVID-19 in a future wave? BMJ. 2021;372:n70. doi:10.1136/bmj.n70

24. Vermote B, Waterschoot J, Morbee S, et al. Do psychological needs play a role in times of uncertainty? Associations with well-being during the COVID-19 crisis. J Happiness Stud. 2021. doi:10.1007/ s10902-021-00398-x

25. Hollebeek LD, Smith DLG, Kasabov E, Hammedi W, Warlow A, Clark MK. Customer brand engagement during service lockdown. J Serv Mark. 2020;35(2):201-209. doi:10.1108/jsm-05-2020-0199

26. China News. Nanjing epidemic cannot be ignored! Why is the airport "broke defence"? in Chinese; 2021. Available from: https://baijiahao. baidu.com/s?id=1706229935174222142\&wfr=spider\&for=pc. Accessed August 1, 2021.

27. Xinhua News Agency. Lax management leads to COVID-19 infections at the Nanjing airport; 2021. Available from: http://www.xinhuanet.com/ english/2021-08/03/c 1310105566.htm. Accessed November 15, 2021.

28. China Daily. Cluster of infections points to theater in Zhangjiajie; 2021. Available from: http://global.chinadaily.com.cn/a/202107/30/ WS610337b0a310efa1bd665626.html. Accessed November 15, 2021.

29. Fox News. China's Inner Mongolia quarantines tourists over virus fears; 2021. Available from: https://www.fox44news.com/news/chi nas-inner-mongolia-quarantines-tourists-over-virus-fears/. Accessed November 15, 2021.

30. Daphna-Tekoah S, Megadasi Brikman T, Scheier E, Balla U. Listening to hospital personnel's narratives during the COVID-19 outbreak. Int $J$ Environ Res Public Health. 2020;17(17):6413. doi:10.3390/ijerph17176413

31. Zhang X, Yang S. "A community system": a critical foundation for the epidemic prevention and control of SARS-CoV-2. Int $J$ Health Plann Manage. 2020;35(5):1246-1249. doi:10.1002/hpm.3005

32. Kaur S, Bherwani H, Gulia S, Vijay R, Kumar R. Understanding COVID-19 transmission, health impacts and mitigation: timely social distancing is the key. Environ Dev Sustain. 2021;23:6681-6697. doi:10.1007/s10668-020-00884-x

33. Maslow AH. A theory of human motivation. Psychol Rev. 1943;50:370-396. doi:10.1037/h0054346

34. Yin RK. Case Study Research: Design and Methods (5th Ed.). Thousand Oaks, CA: Sage; 2014.

35. Net Ease. The number of cases in Liwan, Guangzhou increased to 6, and the morning tea restaurant became the transmission center. in Chinese; 2021. Available from: https://www.163.com/dy/article/ GAU85LK20514R9P4.html. Accessed July 3, 2021.

36. People's Daily. The transmission chain of the epidemic in Liwan, Guangzhou increased to 77 people, 1 person in Hainan village directly infected 15 people. in Chinese; 2021. Available from: https://baijiahao.baidu.com/s?id=1701529683139199533\&wfr=spi der\&for=pc. Accessed July 3, 2021. 
37. CCTV News. Over 0.12 million nucleic acid tests completed are negative at Liwan District of Guangzhou. in Chinese; 2021. Available from: https://baijiahao.baidu.com/s?id= $1700635756928464684 \& w f r=$ spider\&for $=$ pc. Accessed November $15,2021$.

38. Government at Liwan District of Guangzhou. Notice on the resumption of business activities of catering service units in northern Liwan. in Chinese; 2021. Available from: http://www.lw.gov.cn/lwzx/tzgg/ content/post_7350359.html. Accessed July 3, 2021.

39. Xinhua. Caregivers of patients with diagnosed once group chatting! Harbin Health Commission disclosed the cause of nosocomial infection for the first time. in Chinese; 2020. Available from: https:// baijiahao.baidu.com/s?id=1664663418677180790\&wfr=spider\&for= pc. Accessed July 3, 2021.

40. China Economy. Harbin's Coronavirus Disease has extended the chain of infections: more than 80 people have been infected, and many questions remain to be resolved. in Chinese; 2020. Available from: ht tps :// b a i j i hao.baidu.com / s ? id = 1664996964785495545\&wfr=spider\&for=pc. Accessed July 3, 2021.

41. Youth NET. 11 new confirmed cases in Zhengzhou, the epidemic mainly occurred inside the hospital, involving medical personnel. in Chinese; 2021. https://t.ynet.cn/baijia/31201200.html. Accessed November 13, 2021.

42. Lades LK, Laffan K, Daly M, Delaney L. Daily emotional well-being during the COVID-19 pandemic. Health Psychol. 2020;25(4): 902-911. doi:10.1111/bjhp. 12450

43. Morina N, Kip A, Hoppen TH, Priebe S, Meyer T. Potential impact of physical distancing on physical and mental health: a rapid narrative umbrella review of meta-analyses on the link between social connection and health. BMJ Open. 2021;11(3):e042335. doi:10.1136/bmjopen-2020-042335

44. Reuters. China COVID-19 cases surge to high in over 10 months; 2021. Available from: https://news.yahoo.com/china-reports-138covid-19-004330362.html. Accessed February 1, 2021.

45. Qin S, Ding Y. Why not see a doctor when ill? Evidence from the Chinese elderly. BMC Health Serv Res. 2019;19:365. doi:10.1186/ s12913-019-4212-0

46. Ji M, Zhang Y, Zou J, et al. Study on the status of health service utilization among caregivers of left-behind children in poor rural areas of Hunan province: a baseline survey. Int $J$ Environ Res Public Health. 2017;14(8):910. doi:10.3390/ijerph14080910
47. China Economy. Recalling everyone contacted within 2 weeks, the "Uncle Xicheng", the first confirmed patient of the epidemic in Beijing, was praised as "the strongest brain". in Chinese; 2020. Available from: https://baijiahao.baidu.com/s?id= 1669818995243945051\&wfr=spider\&for=pc. Accessed July 3, 2021.

48. Tencent News. The epidemic in Beijing was under control, and the "uncle" made a great contribution. in Chinese; 2020. Available from: https://new. qq.com/rain/a/20200618A0PLKZ00. Accessed July 3, 2021.

49. Global Times. The 34-year-old postgraduate entrance examination was positive for nucleic acid! Emergency notification for the two places. in Chinese; 2020. Available from: https://baijiahao.baidu.com/s?id= $1687006768439830137 \& w f r=$ spider \&for=pc. Accessed September 5, 2021.

50. Eastday. The man who passed the postgraduate entrance examination tested positive! Emergency notification for the two places, announcement with detailed trajectory. in Chinese; 2020. Available from: https://www.sohu.com/a/440282320_120823584. Accessed June 3, 2021.

51. Cyberspace Administration of China. The 45th China statistical report on internet development; 2020. Available from: http://www. cac.gov.cn/2020-04/27/c_1589535470378587.htm. Accessed October 26, 2020.

52. Cyberspace Administration of China. The 44th China statistical report on internet development; 2019. Available from: http:/www.cac.gov.cn/201908/30/c_1124938750.htm. Accessed October 26, 2020.

53. Tencent News. 144 infected by one! The chain of "super spread" in Jilin extended, and this epidemic presents five features. in Chinese; 2021. Available from: https://new.qq.com/omn/20210120/ 20210120A0AF5F00.html. Accessed February 1, 2021.

54. Tencent News. Yangzhou has become a "new storm eye", and 7 places of Kaifeng have upgraded high-risk epidemic prevention and control, ringing the alarm of normalization. in Chinese; 2021. Available from: https://new.qq.com/rain/a/20210808A0ACU100. Accessed November 15, 2021.

55. China Daily. COVID-19 vaccination begins for people older than 60 ; 2021. Available from: https://www.chinadaily.com.cn/a/202103/21/ WS60570a40a31024ad0bab07db.html. Accessed November 15, 2021.

56. Guangming Daily. More than 100 million people stay put for this Spring Festival. in Chinese; 2021. Available from: https://m.gmw.cn/ baijia/2021-02/11/1302106284.html. Accessed November 15, 2021.
Risk Management and Healthcare Policy

\section{Publish your work in this journal}

Risk Management and Healthcare Policy is an international, peerreviewed, open access journal focusing on all aspects of public health, policy, and preventative measures to promote good health and improve morbidity and mortality in the population. The journal welcomes submitted papers covering original research, basic science, clinical \& epidemiological studies, reviews and evaluations, guidelines, expert opinion and commentary, case reports and extended reports. The manuscript management system is completely online and includes a very quick and fair peer-review system, which is all easy to use. Visit http://www.dovepress.com/testimonials.php to read real quotes from published authors. 